\title{
El CONICET en el marco de la última dictadura cívico-militar (1976-1983): entre el disciplinamiento represivo y un crecimiento diferencial-descentralizado
}

Reseña de: Fabiana Bekerman (2018). La investigación científica argentina en dictadura. Transferencias y desplazamientos de recursos (1974-1983). Mendoza. Editorial EDIUNC. 168pp.

Gonzalo Miguel Castillo

Instituto de Investigaciones Socio-Económicas de la Universidad Nacional de San Juan /

CONICET, Argentina

castigonzalo@gmail.com

¿Cómo es posible que un gobierno de facto, de explícitas orientaciones conservadoras en lo político, oscurantistas en lo cultural y desindustrializadoras en lo económico haya incrementado progresiva, así como heterogéneamente su presupuesto destinado a ciencia y técnica? ¿Quiénes fueron los arquitectos y cuál fue el grado de autonomía de los ejecutores de aquellas políticas científicas? Estas preguntas invitaron a Fabiana Bekerman a dar inicio a una rigurosa, prolija y reflexiva investigación doctoral, la cual ha sido desplegada en la presente obra. La puesta en discusión de algunas dimensiones del sentido común que envuelve a uno de los periodos más trágicos de la historia argentina, cuyas secuelas subsisten y laceran en la actualidad, le ha permitido a la autora desentramar el complejo nudo en torno a la política científica y tecnológica digitada durante la última dictadura militar, que tuvo lugar en Argentina durante los años 1976-1983. En efecto, este libro da cuenta, entre otros, de dos destacados hallazgos: hubo un proceso de transferencia y desplazamiento de los recursos económicos de las universidades nacionales hacia el Consejo Nacional de Investigaciones Científicas y Técnicas (CONICET), y, a su vez, dicho organismo proliferó de modo descentralizado a partir del emplazamiento de institutos de investigación en diferentes latitudes del país.

Bekerman es doctora en Ciencias Sociales con mención en Sociología por la Universidad Nacional de Cuyo, investigadora de la Carrera del Investigador Científico del CONICET, integra el Programa de Investigaciones sobre Dependencia Académica en América Latina (PIDAAL), con sede en Mendoza. Ha coordinado diversos estudios nacionales y participado en numerosos equipos de investigación. Es autora de capítulos de libros y de varias publicaciones en revistas científicas nacionales e internacionales temáticamente vinculadas a la política científico-universitaria, entre las cuales se destacan: "Distribución desigual de las capacidades de investigación en las ciencias sociales argentinas: una mirada relacional" (2018), "Morfología del espacio científico-universitario argentino: una visión de largo plazo (1983-2014)" (2017), "Les instituts de recherche: expansion et reconfigurationdans le champscientifiqueargentinpendant le derniergouvernementmilitaire (1976-1983)" (2013), "TheScientific Field duringArgentina'sLatestMilitaryDictatorship (1976-1983): Contraction of PublicUniversities and Expansion of theNational Council forScientific and TechnologicalResearch (CONICET)" (2013), "La expansión de las researchcapacities en tiempos de dictadura: la política de creación de institutos en el CONICET y su impacto en la estructura del sistema científico argentino (1974-1983)" (2011), entre otros.

La obra, prefaciada y prologada por los referentes en el área Diego Hurtado y Carolina Kaufmann, respectivamente, ha sido estructurada en dos partes generales. La primera da cuenta del enfoque epistemológico-conceptual que orientó la investigación, como así también del diseño metodológico de la misma. Además, introduce al lector en el proceso de modernización universitario experimentado entre los años 1950 y 1970 en la región latinoamericana, ajustando la lente analítica en Argentina. La segunda avanza 
sobre el análisis de la política científica desplegada durante la dictadura, con focoen dos movimientos: unode "contracción y disciplinamiento del campo científico-universitario", y otro de "reorientación de los recursos presupuestarios, expansión y descentralización” del CONICET.

El texto, en su primer capítulo, despliega el proceso de delimitación del objeto de estudio, a partir del cual se ha ido comprendiendo cómo diversos acontecimientos políticos desarrollados a principios de la década de 1970 impactaron en el campo científico-universitario argentino, lo que permiteexplicar el golpe de Estado del año 1976. Entre ellos, se destacan las intervenciones del presidente Héctor Cámpora a las universidades nacionalespara eliminarlos exámenes de ingreso, así como al CONICET para suprimirsu directorio y designar un interventor hacia el año 1973. Ahora bien, un hito significativo consistió en el nombramiento de Oscar Ivanissevichcomo ministro de Educación en 1974. Su gestión daría inicio a las acciones de intervención y represión militar en el ámbito universitario, que recrudecerían aniveles inusitados a partir de la dictadura iniciada en 1976.

El estudio ha sido desarrollado a partir de un enfoque epistemológico-conceptual doble, erigido sobre la base de la sociología reflexiva de Pierre Bourdieu, articulada con el "método histórico-estructural originado en el estructuralismo cepaliano y la perspectiva de los estudios sociales de la ciencia en periferia" (Bekerman, 2018, p.27). En cuanto a las categorías conceptuales bourdianas, es preciso destacar que el sociólogo francés entiende el concepto de campo como un espacio estructurado de posiciones y de luchas entre diferentes agentes que irán ocupando distintas posiciones en pos de acumular un capital desigualmente distribuido, con el objeto de escindirse de las visiones irénicas de conceptos como el de comunidad científica propuesto por Thomas Khun. Además, quien se prepara para incorporarse a un campo determinado, como el científico, se ha hecho con un particular interés previo por el mismo, por sus reglas y por su capital específico, el cual, en el caso de esta obra, remite al capital científico, definido por Bourdieu como el monopolio de la autoridad científica.

Sin embargo, a lo largo de este libro se explicitará que en el campo científico universitario público argentino entre 1974-1983 convivieron dos tipos de capitales, el científico y otro vinculado al poder institucional de los directores de institutos impuestos por el gobierno militar.Dicha imposición, entre otras, digitada por fuerzas exógenas,llevó a Bekerman a desplegar una nutrida lectura analítica de la categoría conceptual de autonomía-junto a la propuesta de Fernanda Beigel en el marco del PIDAAL-,en la que se abordanlos tres usos de la misma: "vinculado a la especialización de lo académico como espacio social", respecto a la “institucionalización de las escuelas de enseñanza y definición disciplinar en América Latina”, y en referencia "al impacto de la internacionalización del espacio científico".

El abordaje metodológico presenta una estructura de dos instancias, una orientada a la reconstrucción empírica y analítica del objeto de estudio y otra focalizada en la trayectoria de los agentes que conformaban el campo científico-universitario estudiado. Esto le permitió a la autora construir un corpus de datos compuesto por documentación propia del CONICET, la SECYT, la UBA, la UNLP, entre otros organismos. Además, avanzó sobre una reconstrucción biográfica colectiva de los directores a partir de sus curriculum vitae. En cuanto al acceso estadístico, la obra detalla su construcción a partir de una novedosa herramienta denominada Análisis de Correspondencias Múltiples (ACM). Finalmente, el acceso etnográfico tuvo su desarrollo mediante entrevistas en profundidad a ex funcionarios de la dictadura y a personas que conocían de primera mano el funcionamiento del CONICET. Los últimos se desempeñan o desempeñaban en cargos directivos del Consejo, el ex MINCYT o el Ministerio de Educación. Una destacada mención merece la rigurosa pesquisa documental desarrollada por la autora, quien ha debido afrontar en múltiples instancias los efectos de la sistemática desaparición de información que caracteriza a los gobiernos anticonstitucionales.

El capítulo II caracteriza el recorrido de los procesos de institucionalización de la investigación científica en América Latina, originados durante la segunda mitad del siglo XX. En estas latitudes comenzaron a entrar en funciones diversos organismos afines, el primero de los cuales fue la CEPAL en 1949. En años subsiguientes 
serían creados los consejos o comisiones nacionales de investigaciones científicas de países como Brasil, Uruguay, Chile, Colombia, Perú, Ecuador y Argentina, contexto en el que fue instituido el CONICET.

Dicho organismo cumplía la función de promover y coordinar las investigaciones puras y aplicadas. Respecto a su gobierno, cabe señalar que estaba compuesto por un directorio, presidido por Bernardo Houssay, y por otros representantes, cuya amplia mayoría provenía de las ciencias biomédicas. Durante los primeros lustros de vida del Consejo pudo advertirse la existencia y pugna de dos modelos contrapuestos en torno a "la promoción y gestión de la ciencia" (Bekerman, 2018, p.48). Aquellos tomaron entidad en dos grupos diferenciados: uno liderado por Bernardo Houssay, con carácter tradicionalista y de orientación antiperonista, y otrocentrado en la figura de Rolando García, con una visión más moderna de la ciencia vinculada a "un panorama más amplio de necesidades sociales y a un proyecto político más amplio" (Bekerman, 2018, p.49). En tanto, sus instrumentos de promoción fueron la carrera del investigador científico, la carrera del personal de apoyo a la investigación y desarrollo, un programa de becas y una política de creación de institutos de paulatino crecimiento, que tuvo su cenit a partir de 1976. A las luchas internas se les sumaron diversas presiones externas tales como intervenciones, tanto de institutos como del propio directorio del organismo, las cuales llegaron a su punto más álgido a partir de la última dictadura cívicomilitar desplegada en Argentina.

En cuanto al devenir de la educación superior en América Latina, la obra señala su expansión como sistema, y remarca el crecimiento y la feminización de su matrícula durante la década de 1950. Aquellas tendencias acompañaron un proceso modernizador que contó con la institucionalización de nuevas carreras, nuevos métodos docentes y la inauguración de nuevas funciones,así como servicios. No obstante, dicho empuje fue interrumpido por la ola de golpes militares que azotó la región entre las décadas de 1960-1970. Uno de los debates respecto a la educación superior y el rol del Estado que ganó destacada entidad en aquel contexto se cristalizó a partir de la sanción de la denominada Ley Domingorena-de1959 durante la presidencia del Arturo Frondizi-, la cual autorizaba la creación de universidades privadas en el territorio argentino. Por su parte, el periodo abierto a partir del pronunciamiento militar del año 1966 inició con violentos intentos de despolitizar la universidad. Sin embargo, fueron replegándose de modo progresivo en vistas de la resistencia estudiantil contra el avasallamiento de derechos, la cual desde sus inicios contó con el apoyo del movimiento obrero. Al retornar al país y a la presidencia de la Nación en 1974, Juan Domingo Perón promulgó la Ley Universitaria Orgánica. Ella, en líneas generales, garantizaba la autonomía académica, la autarquía económica y financiera, y suprimía, además, el examen de ingreso. Ahora bien, la muerte del líder del Partido Justicialista y la designación de Oscar Ivanissevich en la cartera de educación fueron la antesala de la represión y persecución que la comunidad universitaria y la Argentina en general atravesarona partir del 24 de marzo de 1976.

En su capítulo III, esta obra señala cómo las fuerzas armadas que encabezaron el golpe militar de 1976 decretaron como primeras medidas la caducidad del mandato de las autoridades democráticas, la cesantía de los integrantes de la Corte Suprema de Justicia, la nulidad de derechos sociales tales como el derecho a la participación política, gremial,el derecho a huelga, entre otros. Fueron intervenidos, además, los principales polos industriales; se conformaron listas negras de personas, y hubo arrestos masivos. En el campo educativo se desplegó un control ideológico asfixiante, que dejaría como saldo la desaparición, encarcelamiento y exilio forzado de un impresionante número de personas.

En cuanto al análisis de la política científica en dictadura, en la obra se despliega un estudio de los grados de autonomía en dos vínculos particulares: entre el poder político y el campo científico, y, en el interior del segundo, entre los investigadores y la institución. En efecto, el año 1981 fue decisivo para el CONICET, dado que se implementó la ley No 22.520, denominada como Ley de Ministerios, que trasladaba a la Secretaría de Ciencia y Técnica (SECYT) a Presidencia de la Nación. En este contexto se rearmó el directorio del Consejo, el cual quedó integrado por trece científicos, un representante de la SECYT y otro de los institutos de investigación de las fuerzas armadas. Entre otras cosas, puede mencionarse que 
dicho directorio disponíade pequeñas cuotas de autonomía. Esto puede vislumbrarseen sus actas, en las cuales se plasmala constante presencia del ministro de Educación discutiendo temas sensibles en materia presupuestaria. Cabe destacar que las presiones hacia el CONICET fueron tanto económicas como políticas. Las últimas desplegaron un abanico de procedimientos disciplinatorios que, en líneas generales, consistían en la expulsión por causas ideológicas, la relocalización de nuevos agentes en posiciones jerárquicas y la concentración de cargos directivos en pocas personas. En cuanto a la relocalización de investigadores y concentración de cargos jerárquicos la obra destaca que, si bien en su mayoría eran investigadores reconocidos en el campo, la mayoría comenzó a ocupar posiciones jerárquicas durante el periodo estudiado.

El accionar de la dictadura representó el embate más profundo del siglo XX a la autonomía universitaria. En efecto, a los dispositivos de represión ya conocidos, se sumó un complejo proceso de militarización de la enseñanza pública que permitió la intromisión del gobierno militar en el seno de las universidades. Entre otras medidas, en el año 1980 fue publicada de Ley No 22.207, que reglamentaba el funcionamiento de las universidades nacionales, y que establecía como objetivo principal "el reordenamiento jurídico del funcionamiento de las universidades en función de los fines propuestos por el Proceso de Reorganización Nacional" (Bekerman, 2018, p.91). En concordancia, buscaba eliminar todo pensamiento político de la esfera universitaria y otorgara la dictadura un marco institucional para continuar con su represión.

El último capítulo centra su lente analítica en una de las finalidades del Presupuesto General de la Administración Nacional (PGAN) durante la última dictadura, particularmente en la denominada Finalidad 8 Ciencia y Técnica, "que especifica el gasto y la inversión relacionados con la investigación científica y tecnológica” (Bekerman, 2018, pp. 97-98). Entre otros hallazgos, se destaca que sus partidas fueron incrementándose progresivamente durante la última dictadura, aunque de modo heterogéneo entre los diferentes organismos nacionales de CyT. Especialmente las universidades nacionales sufrieron una pérdida abrupta de su presupuesto, que pasó del 26\% al 8\% entre los años 1975-1976. Ahora bien, en particular el CONICET experimentó aumentos inusitados en su participación presupuestaria.El Consejo tuvo un crecimiento excepcional; partió del 10\% en 1974, llegóal 25\% en 1975, y alcanzó una ratio máxima del 31\% en 1981, lo que corrobora un proceso de transferencia de recursos de las universidades nacionales hacia el CONICET. De modo conducente, se evidenció un progresivo y descentralizado crecimiento de los institutos de investigación, que pasaron de 55 en el año 1976 a159 en 1982.

La magnitud de la expansión de institutos y su falta de correlato con la producción CyT generó la hipótesis de que algunos espacios de investigación habrían funcionado "como una especie de carcasa creada como resultado de intereses personales y sin sustrato real” (Bekerman, 2018, p.109). Una característica destacada de dicho proceso consistía en que los directores de los institutos eran los responsables del manejo de los subsidios entregados por el Consejo. En sintonía, generó destacada relevancia el denominado Programa BIDCONICET, que consistió en el desembolso de un empréstito capaz de financiar el programa de creación de centros regionales del CONICET propuesto en 1976. Los fondos otorgados por el organismo internacional coadyuvaron a materializar la política de descentralización, a partir de la creación decuatro centros regionales: CRIBABB, CRICYT, CERIDE y CNP.

Los resultados hasta aquí reseñados posibilitaron desplegar un análisis relacional de la nueva estructura del campo científico, surgida de la política científica implementada por la dictadura. En este sentido, la autora recurre a la implementación del ACM que "permitió proyectar los individuos estadísticos (institutos de investigación) en un plano factorial, creando un espacio pluridimensional en el cual se distribuyen las propiedades (variables y modalidades) y sus poseedores (institutos y directores) conformando una estructura de relaciones" (Bekerman, 2018, p.124). La aplicación del ACM permitió-dicho en apretadísima síntesisidentificar cuatro perfiles de institutos posicionados en el campo científico público argentino. El primero, denominado como antiguos lo componían los espacios de investigación consagrados, cuyos directores poseían un elevado capital científico y poder institucional. El segundo grupo, clasificado como impuestos acumulaban menores cuotas de capital científico pero iguales o mayores de poder institucional; fueron creados en 
su mayoría durante la última dictadura. Al tercer grupo, definido como recién llegados, pertenecían los institutos de las universidades emplazadas en las provincias que fueron creados por medio del préstamo del BID, con directores jóvenes. Finalmente, los clasificados como trasplantados fueron institucionalizados durante la primera etapa del gobierno militar, cuyos directores detentaban menor prestigio académico y escaso poder institucional.

Queda por mencionar que la obra desarrollada por Fabiana Bekerman destaca no solamente por su rigurosidad teórica-conceptual y su solidez metodológica, sino también por sus significativas reflexiones, que apuntan a desentramar la estructura del campo científico público argentino en dictadura y que ponen en tensión en varias oportunidades al sentido común. Esta obra invita al lector a una profunda reflexión acerca de un periodo oscuro que todavía interpela a la sociedad Argentina en general y a la comunidad científica en particular. 